\title{
PENERAPAN EIGENFACE UNTUK COMPUTER BASED TEST (CBT) PENERIMAAN MAHASISWA BARU SEKOLAH TINGGI TEKNOLOGI ADISUTJIPTO
}

\author{
Haruno Sajati ${ }^{1}$, Astika Ayuningtyas ${ }^{2}$, Dwi Kholistyanto ${ }^{3}$ \\ Departemen Informatika \\ Sekolah Tinggi Teknologi Adisutjipto Yogyakarta \\ harunosajati@stta.ac.id ${ }^{1}$, astika@stta.ac.id ${ }^{2}$, kholistyanto@gmail.com ${ }^{3}$
}

\begin{abstract}
One of the development of computer technology is the availability of systems or applications that help human work everyday so that can be resolved quickly and correctly. The system, one of which is Computer Based Test (CBT). CBT is an application used for tests conducted using computers that are in the application there are some features of CBT security when working on the problem. CBT can use a stand-alone computer, a computer connected to a network or a computer connected to the internet. Facial recognition is a type of biometric application that can identify specific individuals in a digital image by analyzing and developing face patterns. In its implementation, CBT has a weakness in the security system that becomes the gap of CBT users to commit fraud, therefore required a good security system with the creation of CBT applications that use eigenface algorithm. It is necessary to have a security system that overcomes the problem that is required identification of face recognition of participants during the test so that cheating can be reduced. The results of the test using eigenface algorithm accuracy rate reached $82 \%$, some things that affect the level of accuracy is, the intensity of light, facial position and the use of accessories on the face.
\end{abstract}

Keywords: Computer Based Test, Eigenface, Security and Accuracy

\section{Pendahuluan}

Tes berbasis komputer (Computer Based Test/CBT) adalah tes yang dilakukan menggunakan komputer. CBT dapat menggunakan komputer yang berdiri sendiri, komputer yang terhubung dengan jaringan ataupun komputer yang terhubung dengan internet [1]. CBT memungkinkan tes yang konsisten, proses peniliaian dan pelaporan yang cepat serta keamanan yang lebih baik (GED, 2015). Indonesia telah menggunakan CBT untuk melakukan ujian nasional berbasis komputer (UNBK) pada tahun 2015. UNBK ini diikuti oleh 556 sekolah yang terdiri dari 42 SMP/MTs, 135 SMA/MA, dan 379 SMK di 29 Provinsi dan Luar Negeri. Di masa depan CBT akan diterapkan di semua sekolah [2].

Test berbasis komputer masih memungkinkan peserta ujian melakukan kecurangan. Kecurangan yang biasanya dilakukan pada CBT adalah pemalsuan identitas (joki). Kecurangan dilakukan untuk mendapatkan nilai baik. Kecurangan mengakibatkan tidak layaknya nilai yang diperoleh peserta ujian. Nilai hasil ujian tidak dapat menggambarkan pengetahuan dan kemampuan nilai baik. Kecurangan mengakibatkan tidak layaknya nilai yang diperoleh peserta. Peserta curang biasanya tidak kompeten karena tidak menguasai materi yang diujikan. Gangguan moral akan terjadi jika peserta sering atau selalu melakukan kecurangan.Seorang yang curang akan menganggap orang lain dengan nilai baik melakukan hal yang sama [3].

Kecurangan pada CBT disebabkan lemahnya keamanan aplikasi. Kecurangan dapat terjadi sejak awal atau selama tes berlangsung. Kecurangan sejak awal terjadi jika peserta tes mengunakan joki sejak awal. CBT hanya melakukan identifikasi username dan password pengguna pada saat login. Password dan username dapat dengan mudah diberikan kepada joki. Tidak adanya identifikasi peserta selama tes membuat kecurangan terjadi selama tes. Oleh karena itu, perlu 
membuat suatu sistem yang bisa memvalidasi bahwa seseorang yang terdaftar menjadi peserta ujian pada CBT adalah benar orang yang dimaksud. Dari permasalahan tersebut, perlu adanya penelitian untuk menerapkan sistem deteksi wajah pada user yang mengakses CBT. Pada penelitian ini mengambil studi kasus penerimaan mahasiswa baru di Sekolah Tinggi Teknologi Adisutjipto Yogyakarta dengan menggunakan metode eigenface untuk proses deteksi wajahnya.

\section{Landasan Teori}

\subsection{Aplikasi Tes Berbasis Komputer}

Aplikasi tes berbasis komputer dirancang untuk mengotomasi proses skoring dan interpretasi. Salah satu fitur yang menarik CBT adalah kemungkinan untuk melakukan ujian terus menerus. CBT dapat mebuat pilihan jawaban secara acak untuk menghindari kecurangan peserta ujian [4]. Selain itu, CBT masih memiliki kelemahan dalam hal keamanan seperti peserta ujian masih memiliki kesempatan untuk melakukan kecurangan untuk meningkatkan nilai ujian. Untuk itu penguji berkewajiban untuk mengambil langkah-langkah untuk menjaga keamanan tes [5].

\subsection{Pengolahan Citra}

Pengolahan citra merupakan proses pengolahan sinya yang inputannya berupa citra. Outputnya dapat berupa citra atau sekumpulan karakteristik atau parameter yang berhubungan dengan citra. Istilah pengolahan citra digital secara umum didefinisikan sebagai pemrosesan citra dua dimensi dengan komputer. Dalam definisi yang lebih luas, pengolahan citra digital juga mencakup semua data dua dimensi. Citra digital adalah barisan bilangan nyata maupun kompleks yang diwakili oleh bit-bit tertentu [6].

\subsection{Pengenalan Wajah}

Citra wajah dapat diakusisi dengan menggunakan kamera digital di ruang yang memiliki pencahayaan bagus. Citra wajah bagian depan ditangkap dengan membuat subyek yang berada di depan kamera melihat ke kamera. Wajah bagian samping dapat diambil dengan membuat subyek menghadap agak miring dari kamera. Beberapa citra wajah depan dan samping diekstrak ciricirinya dan kemudian disimpan pada file. Ciri-ciri ini disimpan dalam bentuk vektor. Ciri-ciri yang sama dan sesuai disusun secara berurutan untuk mempercepat proses perhitungan. Wajah yang akan diuji dievaluasi berdasarkan ciri-ciri wajah dibandingkan dengan ciri-ciri wajah pelatihan yang telah disimpan [7].

\subsection{Eigenface}

Eigenface merupakan algoritma pengenalan wajah berdasarkan analisis komponen utama (Principal Component Analysis). Gagasan utama metode ini adalah menguraikan komponen utama citra muka ke dalam satu set eigenfaces (sekelompok kecil karakteristik ciri citra). Algoritma eigenface mengubah pola gambar wajah pelatihan menjadi vektor $\mathrm{M} \times \mathrm{N}$ x $\mathrm{K}$, dimana $\mathrm{M} \times \mathrm{N}$ adalah ukuran gambar dan K adalah jumlah citra pelatihan [7].

\section{Metodologi Penelitian}

\subsection{Analisa Kebutuhan Sistem}

1. Hadware :
a. Processor
: Intel Pentium B960 2,20 GHz
b. RAM
: $2.6 \mathrm{~GB}$
c. Harddisk
: $500 \mathrm{~GB}$
d. Monitor LED
: 14 inchi

2. Software

a. Microsoft Windows 7 32-bit sebagai sistem operasi. 
b. Microsoft Visual C++ 2010 Express sebagai lingkungan terpadu pengembangan aplikasi.

c. Pustaka OpenCV sebagai pustaka penginderaan.

\subsection{Perancangan Sistem}

Diagram alur sistem pada Gambar 1.a dan 1.b menunjukkan arus pekerjaan sistem pada CBT yang menerapkan eigenface secara keseluruhan. Bagan ini menjelaskan urutan prosedur yang ada di dalam sistem.
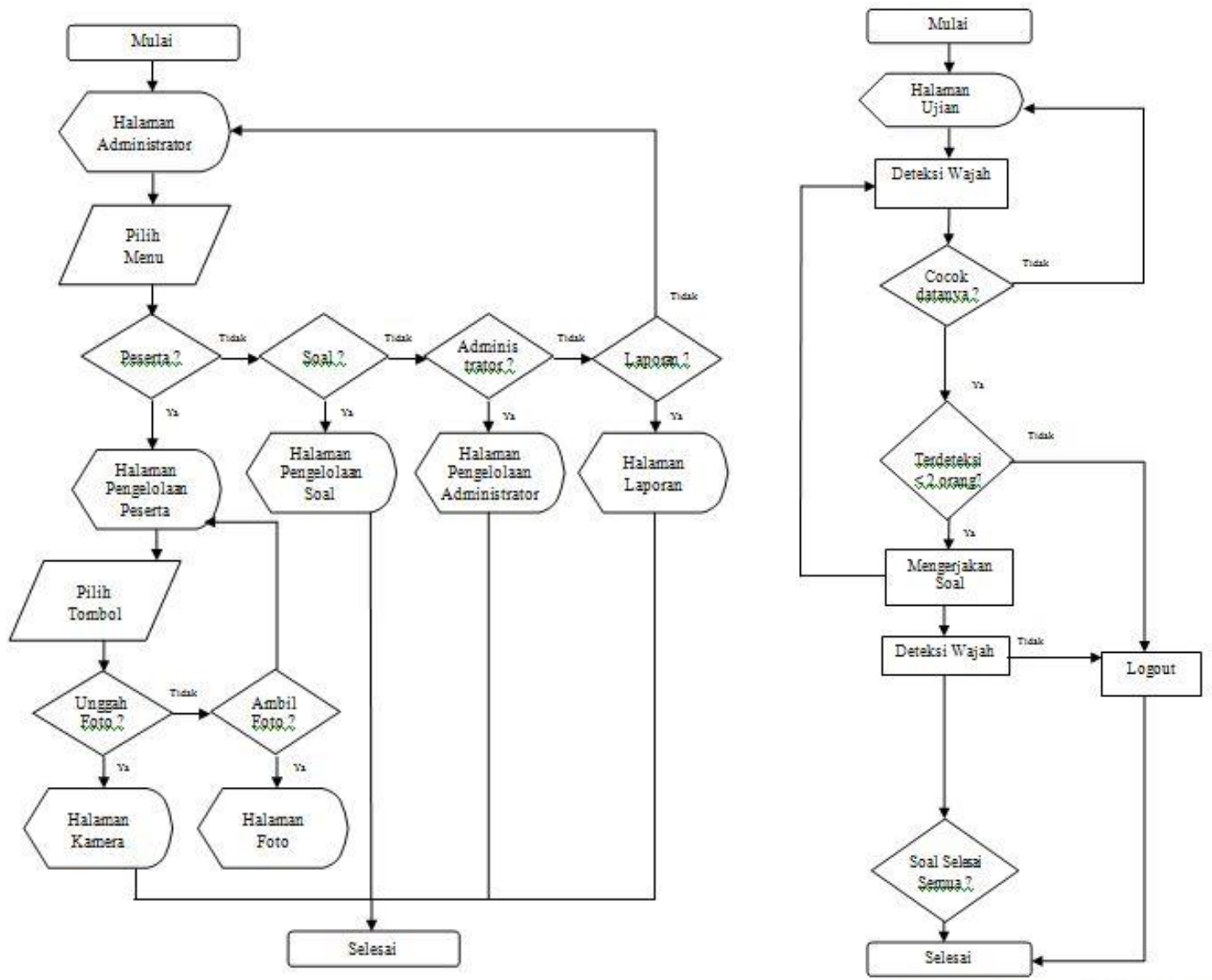

Gambar 1.a. Digram Alur Sistem Pada Admin

Gambar 1.b. Digram Alur Sistem Pada User

Sedangkan pada Gambar 2 menggambarkan arus data antara sistem dengan pengguna yang berhubungan dengan sistem.

\subsection{Diagram Konteks}

Diagram konteks pada Gambar 2, terdapat alur data dari sistem, terdapat dua entitas yaitu administrator dan peserta ujian (user).

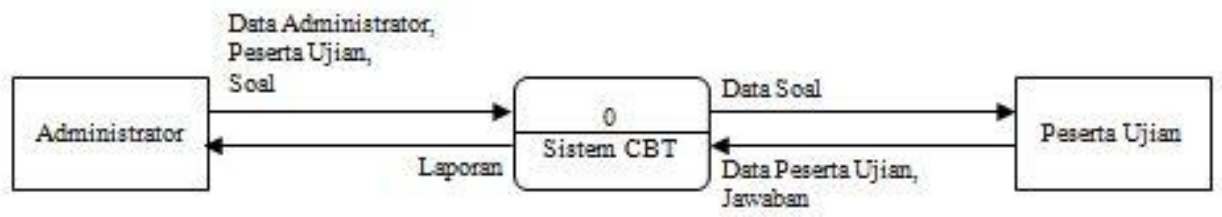

Gambar 2. Diagram Konteks Sistem CBT 


\subsection{Perancangan Antar Muka Sistem CBT Bagian Administrator dan Peserta Ujian}

Pada perancangan antar muka dibagian administrator terdapat menu sesudah login meliputi menu peserta ujian dan menu administrator. Menu peserta ujian memiliki sub menu identitas, unggah, ujian, logout dan keluar seperti yang terlihat pada Gambar 3, sedangkan pada Gambar 4 terdapat tampilan antar muka untuk peserta ujian yang meliputi menu peserta ujian dan menu administrator. Menu peserta ujian memiliki sub menu login, daftar dan keluar.

\begin{tabular}{|c|c|}
\hline Peserta Ujian & Administrator \\
\hline \multirow[t]{7}{*}{ Login } & Peserta Ujian \\
\hline & Kamera \\
\hline & Foto \\
\hline & Soal \\
\hline & Laporan \\
\hline & Administrator \\
\hline & Logout \\
\hline
\end{tabular}

Gambar 3. Rancangan Menu Administrator

\begin{tabular}{|l|l|l|}
\hline Peserta Ujian & Administrator & \\
\hline Login & Login & \\
\hline Daftar & \\
\hline Keluar &
\end{tabular}

Gambar 4. Rancangan Menu Peserta Ujian

\section{Hasil dan Pembahasan}

\subsection{Pengujian Pada Sistem CBT}

Pada semua proses di menu sistem CBT dapat dilihat pada Tabel 1. Ada 2 aktor yang terlibat yaitu administrator dan peserta ujian.

Tabel 1. Hasil Uji Proses Pada Sistem CBT

\begin{tabular}{|c|c|c|c|c|}
\hline No & Aktor & Kasus Penggunaan & Berhasil & Gagal \\
\hline 1 & \multirow[t]{7}{*}{ Administrator } & Melakukan Login & $\sqrt{ }$ & \\
\hline 2 & & Mengelola Identitas & $\sqrt{ }$ & \\
\hline 3 & & Menyimpan Foto & $\sqrt{ }$ & \\
\hline 4 & & Mengelola Foto & $\sqrt{ }$ & \\
\hline 5 & & Mengelola Soal & $\sqrt{ }$ & \\
\hline 6 & & Membuat Laporan & $\sqrt{ }$ & \\
\hline 7 & & Mengelola Administrator & $\sqrt{ }$ & \\
\hline 8 & \multirow[t]{6}{*}{ Peserta Ujian } & Mendaftar & $\sqrt{ }$ & \\
\hline 9 & & Melakukan Login & $\sqrt{ }$ & \\
\hline 10 & & Mengubah Identitas & $\sqrt{ }$ & \\
\hline 11 & & Menyimpan Foto & $\sqrt{ }$ & \\
\hline 12 & & Memvalidasi Wajah & $\sqrt{ }$ & \\
\hline 13 & & Mengikuti Ujian & $\sqrt{ }$ & \\
\hline
\end{tabular}

Hasil uji menu pada proses di CBT dapat diketahui bahwa menu dan sub menu di aplikasi dapat berjalan dengan baik dan benar. Seperti menu admin waktu melakukan login, mengelola identitas, menyimpan foto, mengelola foto, mengelola soal, membuat laporan dan mengelola administrator sedangkan dimenu peserta ujian seperti mendaftar, melakukan login, mengubah identitas, menyimpan foto, memvalidasi wajah, dan mengikuti ujian.

\subsection{Akurasi Pengenalan Wajah}

Tingkat akurasi pengenalan wajah dihitung menggunakan formulir kamera. Pada formulir ini akan diketahui apakah pengenalan wajah dilakukan dengan benar atau tidak terdeteksi. Banyak 
responden yang diuji adalah 30 orang. Masing-masing orang diuji sebanyak 5 kali. Tabel 2. menunjukkan hasil perhitungan akurasi pengenalan wajah.

Tabel 2. Hasil Pengujian Terhadap Akurasi Pengenalan Wajah

\begin{tabular}{|c|c|c|c|c|}
\hline No & Responden & Terdeteksi & $\begin{array}{c}\text { Tidak } \\
\text { Terdektesi }\end{array}$ & Akurasi \\
\hline 1 & Responden 1 & 5 & 0 & $100 \%$ \\
\hline 2 & Responden 2 & 4 & 1 & $80 \%$ \\
\hline 3 & Responden 3 & 3 & 2 & $60 \%$ \\
\hline 4 & Responden 4 & 4 & 1 & $80 \%$ \\
\hline 5 & Responden 5 & 4 & 1 & $80 \%$ \\
\hline 6 & Responden 6 & 3 & 2 & $60 \%$ \\
\hline 7 & Responden 7 & 4 & 1 & $80 \%$ \\
\hline 8 & Responden 8 & 4 & 1 & $80 \%$ \\
\hline 9 & Responden 9 & 5 & 0 & $100 \%$ \\
\hline 10 & Responden 10 & 5 & 0 & $100 \%$ \\
\hline 11 & Responden 11 & 4 & 1 & $80 \%$ \\
\hline 12 & Responden 12 & 3 & 2 & $60 \%$ \\
\hline 13 & Responden 13 & 3 & 2 & $60 \%$ \\
\hline 14 & Responden 14 & 4 & 1 & $80 \%$ \\
\hline 15 & Responden 15 & 5 & 0 & $100 \%$ \\
\hline 16 & Responden 16 & 5 & 0 & $100 \%$ \\
\hline 17 & Responden 17 & 4 & 1 & $80 \%$ \\
\hline 18 & Responden 18 & 3 & 2 & $60 \%$ \\
\hline 19 & Responden 19 & 3 & 2 & $60 \%$ \\
\hline 20 & Responden 20 & 5 & 0 & $100 \%$ \\
\hline 21 & Responden 21 & 5 & 0 & $100 \%$ \\
\hline 22 & Responden 22 & 5 & 0 & $100 \%$ \\
\hline 23 & Responden 23 & 4 & 1 & $80 \%$ \\
\hline 24 & Responden 24 & 4 & 1 & $80 \%$ \\
\hline 25 & Responden 25 & 4 & 1 & $80 \%$ \\
\hline 26 & Responden 26 & 4 & 1 & $80 \%$ \\
\hline 27 & Responden 27 & 5 & 0 & $100 \%$ \\
\hline 28 & Responden 28 & 5 & 0 & $100 \%$ \\
\hline 29 & Responden 29 & 4 & 1 & $80 \%$ \\
\hline \multirow[t]{2}{*}{30} & Responden 30 & 3 & 2 & $60 \%$ \\
\hline & Rerata & 123 & 27 & $82 \%$ \\
\hline
\end{tabular}

Berdasarkan Tabel 2, dapat diketahui bahwa tingkat akurasi pengenalan wajah pada aplikasi adalah $82 \%$. Beberapa hal yang mempengaruhi ketepatan penge- nalan wajah adalah intensitas cahaya, posisi wajah dan penggunaan aksesoris pada wajah. Intensitas cahaya dapat dipengaruhi oleh jenis sumber cahaya, letak sumber cahaya dan tingkat keterangan sumber cahaya. Posisi wajah yang mempengaruhi dapat berupa sudut kemiringan wajah terhadap kamera, baik secara horizontal, vertikal maupun proyeksi miring (oblik). Aksesori wajah yang dapat mempengaruhi pengenalan wajah adalah kacamata, baik bingkai kacamata maupun lensa kacamata. 


\section{Penutup}

\subsection{Kesimpulan}

Berdasarkan implementasi dan pembahasan yang telah dilakukan maka dapat diambil kesimpulan sebagai berikut:

1. Pengenalan wajah berhasil diterapkan pada keamanan aplikasi tes berbasis komputer (CBT) pada saat pergantian soal.

2. Algoritma eigenface untuk pengenalan wajah dapat diterapkan pada keamanan aplikasi tes berbasis komputer.

3. Pengenalan wajah menggunakan algoritma eigenface memiliki nilai validitas yang tinggi sebesar $82 \%$.

\subsection{Saran}

Berdasarkan pengujian yang telah dilakukan pada sistem, maka dapat diajukan saran untuk penelitian selanjutnya sebagai berikut:

1. Mengembangkan aplikasi dalam bentuk client server agar dapat melayani banyak pengguna dalam satu kali waktu.

2. Mengembangkan aplikasi untuk berbagai jenis sistem operasi agar dapat dijalankan pada berbagai jenis sistem operasi.

\section{Daftar Pustaka}

[1] Olsen, J.B. 2000. Guidelines for Computer-Based Testing. https://www.isoc.

Or g/oti/printversions/0500olsen.html. Diakses tanggal 25 Agustus 2016 pukul 11.06 WIB.

[2] Kementrian Pendidikan dan Kebudayaan. 2015. Pengantar. http:// unbk.Kemdikbud.go.id/. Diakses tanggal 25 Agustus 2016 pukul 11.25 WIB.

[3] Cascio, C. 2016. How Will Cheating in School Affect the Rest of Your Life? http://oureverydaylife.com/cheating-school-affect-rest-life-28573.html. Diakses tanggal 25 Agustus 2016 pukul 11.30 WIB.

[4] Bartran, D. dan Hambleton, R.K. 2006. Computer-Based Testing and the Internet Issues and Advances. West Sussex. John Wiley \& Sons Ltd.

[5] Mills, C.N., Potenza, M.T., Fremer, J.J. dan Ward, W.C. 2002. Computer Based Testing Building the Foundation for Future Assessments. New Jersey. Lawrence Erlbaum Associates, Inc.

[6] Gonzales, R.C.; Woods, R.E; Eddins, S.L. 2004. Digital Image Processing Using MATLAB. Pearson LPE

[7] Acharya, T. \& Ray, A.K. 2005. Image Processing : Principles and Applications. New Jersey: John Wiley \& Sons, Inc. 